\title{
Assessing Prevalence of Depression Among General Population of Selected Rural Community- A Descriptive Survey Design
}

Perkash KourGulzar ${ }^{1}$ and Ahmad Bhat ${ }^{2 *}$

${ }^{1}$ Department of Clinical Biochemistry, SKIMS, Srinagar, Jammu and Kashmir, India

${ }^{2}$ Madre Meherban Institute of Nursing Sciences \& Research (MMINSR), SKIMS, Srinagar, Jammu and Kashmir, India

\begin{abstract}
Background and objectives: Depression is an illness that affects both the mind and the body and is a leading cause of disability, absenteeism, decreased productivity and high suicide rates. The study aims to assess the prevalence of depression among rural population of selected village of Kashmir, India.

Methods and findings: A community based survey of depressive symptoms was carried out on a purposive sample of 276 subjects in the age group of 20-80 years, who volunteered to participate in the study were recruited. The research design adopted for the study was descriptive survey design. The Depression was assessed by using the Radloff LS (1977) Centre for Epidemiologic Studies Depression scale: This scale was developed to measure symptoms of depression in rural population.

Results: Out of total 276 recruited subjects, $66.3 \%$ were females, $68.1 \%$ were married, $63.4 \%$ belong to nuclear family and $48.2 \%$ had low socioeconomic status (low income). Maximum representations $(40.9 \%)$ of selected subjects were house workers (housewives). Analysis of information on gender, education, marital status, family income, occupation obtained from this sample of 276 subjects suggested that the overall prevalence of depressive symptoms was slightly higher in males than in females, $p>0.002$ in males, illiterates, $p>0.019$; married, $p>0.002$. Low family income and nuclear family has strongest association with depression. 21-40 years of age also found to be significantly associated with depression.
\end{abstract}

Conclusion: The study concludes that prevalence of depressive symptoms among the rural population is common especially in males, married, illiterates, low family income and nuclear families.

Keywords: Prevalence; Depression; Rural population

\section{Introduction}

Among different psychiatric disorders, depression is the leading disorder in general practice and about one in ten patients seen in the primary care setting suffer from some form of depression [1]. It represents a potential public health problem in the elderly population associated with significant mortality and morbidity [2]. According to WHO conducted study, the most common diagnosis in primary care setting was depression [3]. As per recent reports, by the year 2020, depression will be a supreme benefactor in terms of the global burden of diseases among elderly population [4]. In a cross-sectional study no urban-rural difference in depression was observed among elderly population. However, considering high prevalence of depression among females above 80 years low socio economic and physically in active people [5], the national co-morbidity survey, conducted between 1990 and 1992, estimated the 30-day prevalence of a major depression episode at $4.95 \%$ across the US population between the ages of 15-54 years, with no differences by residence [6]. Majority of rural countries are whole or partial mental health professional shortage areas [7], rural residents with mental health problems may less likely to receive service than persons with better access, 340 million people above the age of 18 suffer from depressive disorders that contribute to a high suicide rate [8]. In one of the large sample epidemiological study from urban South Indian population, the prevalence of depression was $15.1 \%$, age, female gender and lower socio-economic status in this population were significantly associated with depression [2]. A number of studies from Kashmiri population are available regarding depression but results are inconsistent [9-12]. Therefore, the aim of the present descriptive study was to assess the prevalence of depressive symptoms among the population of some selected villages of Kashmir.

\section{Material and Methods}

The study was carried out with approval from concerned ethics committee (Sheri Kashmir Institute of Medical Science, Institutional Ethics Committee). A survey was conducted in the village of Zalpura, Sumbal, Bandipora (in the State of J\&K) India. A total of 276 subjects of village were selected through purposive sample technique. All houses of the village were visited. After taking a proper (verbal and written) consent from the participants, $14-80$ years subjects were interviewed by researcher after obtaining consent. Information on demographic characteristics (age, sex, education, marital status, family status, income, occupation) was collected through interviewer- administered and well-designed questionnaire. The depressive symptoms were assessed by using the Radloff LS (1977) centre for Epidemiologic Studies Depression (CES-D) scale [13].

\section{Results}

A total of 276 subjects were recruited in the current study. There were no adverse events during the course of the study and all

*Corresponding author: Dr Gulzar A Bhat, Senior Resident, Department of Clinical Biochemistry, SKIMS, Srinagar, Jammu and Kashmir, India, Tel: 9596503543; E-mail: gulzarbio@gmail.com.

Received: January 03, 2018; Accepted: April 04, 2018; Published: April 17, 2018

Citation: Bhat GA, Kour P (2018) Assessing Prevalence of Depression Among General Population of Selected Rural Community- A Descriptive Survey Design. J Psychiatry 21: 445. doi:10.4172/2378-5756.1000445

Copyright: ๑ 2018 Bhat GA, et al. This is an open-access article distributed unde the terms of the Creative Commons Attribution License, which permits unrestricted use, distribution, and reproduction in any medium, provided the original author and source are credited 
participants assessed provided complete data. Minimum age of subjects was 14 years and maximum age was 93 years. Prevalence of depression was found to be more common among females (66.3) as compared to males (33.7\%). majority of subjects $(75.4 \%)$ were illiterate, $68.1 \%$ were married and $31.9 \%$ unmarried, $63.4 \%$ belong to nuclear family, 34.8 joint family, $1.8 \%$ belong to single family, $48.2 \%$ have low family income, $36.2 \%$ belong to average family, $40.9 \%$ were housewives (Table 1). The association of depressive symptoms with selected demographic variables identified were more in males 10.49 , illiterates 9.83 , married 10.01 , and was significant in low income and single family, $P$ value 0.040 (Table 1). Maximum representation of subjects with depression was shown by the age group of $21-40$ years (38.40\%) followed by $20 \%$ of 41-60 years age group (Table 2).

\section{Discussion}

The current study assesses the prevalence of depression among general population of rural community. We observed that depression was more common among females, illiterate, married people, people living as nuclear families, low income families and among housewives. Similarly, increased prevalence was seen in subjects with age group of

\begin{tabular}{|c|c|c|c|}
\hline Variable & Frequency & percentage & $P$ value \\
\hline \multicolumn{4}{|c|}{ Gender } \\
\hline Male & 93 & 33.7 & \multirow{2}{*}{0.002} \\
\hline Female & 183 & 66.3 & \\
\hline \multicolumn{4}{|c|}{ Education } \\
\hline Illiterate & 208 & 75.4 & \multirow{2}{*}{0.019} \\
\hline Literate & 68 & 24.6 & \\
\hline \multicolumn{4}{|c|}{ Marital status } \\
\hline Married & 188 & 68.1 & \multirow{2}{*}{0.002} \\
\hline Unmarried & 88 & 31.9 & \\
\hline \multicolumn{4}{|c|}{ Family status } \\
\hline Joint & 96 & 34.8 & \multirow{3}{*}{0.040} \\
\hline Nuclear & 175 & 63.4 & \\
\hline Single & 5 & 1.8 & \\
\hline \multicolumn{4}{|c|}{ Family income } \\
\hline Average & 100 & 36.2 & \multirow{5}{*}{0.023} \\
\hline Good & 9 & 3.3 & \\
\hline Low & 133 & 48.2 & \\
\hline Middle & 29 & 10.5 & \\
\hline Moderate & 5 & 1.8 & \\
\hline \multicolumn{4}{|c|}{ Occupation } \\
\hline Carpet weaver & 25 & 9.0 & \multirow{7}{*}{0.033} \\
\hline Farmer & 48 & 17.3 & \\
\hline Housewives & 113 & 40.9 & \\
\hline Laborer & 42 & 15.2 & \\
\hline Shawl weaver & 10 & 3.6 & \\
\hline Student & 22 & 7.9 & \\
\hline Tailor & 4 & 1.44 & \\
\hline
\end{tabular}

Table 1: General characteristics of study subjects $(n=276)$.

\begin{tabular}{|c|c|c|}
\hline \multicolumn{2}{|l|}{ Scale } & N (\%age) \\
\hline \\
\cline { 1 - 2 } & Age & P value \\
\hline $21-40$ & $49(17.74)$ & \\
\hline $41-60$ & $106(38.40)$ & \multirow{2}{*}{$\mathbf{0 . 0 0 2}$} \\
\hline $61-80$ & $57(20.65)$ & \\
\hline$>81$ & $31(11.23)$ & \\
\hline Total & $33(11.95)$ & \\
\hline \multicolumn{2}{|c|}{ Table 2: Age distribution of recruited depression subjects. }
\end{tabular}

Table 2: Age distribution of recruited depression subjects.

\section{1-40 years}

In our study women had higher prevalence of depression which is consistent with earlier published reports $[5,14,15]$. Our results are in agreement with previously published reports [16]. Chandran and Tharayan conducted an epidemiological study which reports women are roughly twice as likely as men to experience or report depression [10]. However, it is of interest that another study done in India among young adults attending college, males were found to have more depression than females [17]. The depressed symptoms were high among the age related decline in central serotonergic function which might make older individuals more vulnerable to depression.

Education is having a great impact on the mental setup of an individual [18]. The higher prevalence of depression among illiterate people in the current study is in compliance with previous reports $[3,19]$. It is possible that India being a developing country and there being an association between depression and lower-socio economic status. Studies have reported a strong association of socioeconomic status and depression $[15,20,21]$. Most of the studies have observed a higher trend in depression related disorders among people with low income people [21,22]. In India, the joint family system was in vogue till recently this provided social security to younger individuals. Recent studies have reported that the lifetime prevention of a major depressive disorder in the United States was $16.2 \%$ [23] whereas the life time prevalence in Europe was 14\% [24]. In 1992 Illinois in USA showed that depression was rise in later life (60 years) which reflected life cycle gains and losses related to marriage, employment and economic well-being [22]. Interestingly, more number of depressive subjects at younger age in our study reflects the "life in conflict" - the Kashmiri people are living since few decades [9]. However, maximum reports have shown an increasing trend in depression with an advancement of age [20,2530]. The other plausible reason could be due to breakdown of the joint family and the emergence of the nuclear family at younger ages due to reduced family support [2].

The results of this study should be viewed in light of a few potential limitations. First, the data was self-reported which may have led to socially desirable responses from majorly illiterate population. Second, this was an observational study wherein cause and effect relationships could not be established. Third, the sample size was limited representing a small portion of population and thus results cannot be generalized to the entire population of Kashmir.

Considering our observations and keeping in view few potential limitations, we could not strongly propose any preventive or interventional actions with the study population. However, there are general suggestions one could hypothesize for the population under depression. Social interaction is frequently reported as a protective factor against a range of negative outcomes, it results in reduction of affective and physiological responses to the stressful event which, in turn, may alter potentially maladaptive behavioural responses. Since, increasing age, illiterate subjects, nuclear families and subjects with low socioeconomic status were with highest representation in current study. Thus, educating people regarding importance of social interaction and generating ways to strengthen their economic status could help in reducing the burden of depression among study population. Subjects should also be routinely monitored for common metabolic disorders like hypertension, diabetes, Obesity, Asthma etc. during their treatment. Implementing gender sensitive and specific programs to target and advance literacy levels may be key to ultimately reducing depression [31]. Depression and anxiety were negatively correlated with physical activity and thus may require additional attention. Such technology- 
Citation: Bhat GA, Kour P (2018) Assessing Prevalence of Depression Among General Population of Selected Rural Community- A Descriptive Survey Design. J Psychiatry 21: 445. doi:10.4172/2378-5756.1000445

supported strategies have great potential to reach underserved populations and address physical activity-related health disparities in study population [32].

\section{Conclusion}

In light of the greater prevalence of depression among rural populations, rural shortages of mental health personnel should be addressed. Rural safety net programs should cooperate with each other and with the community to provide access to mental health services.

\section{Competing Interest}

The authors declare no competing interests.

\section{References}

1. Wittchen HU, Pittrow D (2002) Prevalence, recognition and management of depression in primary care in Germany: the Depression 2000 study. Hum Psychopharmacol 17

2. Poongothai S, Pradeepa R, Ganesan A, Mohan V (2009) Prevalence of depression in a large urban South Indian population-The Chennai Urban Rural Epidemiology study (CURES-70). PLoS One 4: e7185.

3. Goldney RD, Fisher LJ, Wilson DH, Cheok F (2002) Mental health literacy of those with major depression and suicidal ideation: an impediment to help seeking. Suicide Life Threat Behav 32: 394-403.

4. Kale S (2014) A descriptive study to assess prevalence of depression among geriatric group (age 60 years and above). Asian Journal of Multidisciplinary Studies.

5. Vancampfort D, Stubbs B, Sienaert P, Wyckaert S, De Hert M, at al. (2015) What are the factors that influence physical activity participation in individuals with depression? A review of physical activity correlates from 59 studies. Psychiatr Danub 27: 0-224.

6. Blazer DG, Kessler RC, McGonagle KA, Swartz MS (1994) The prevalence and distribution of major depression in a national community sample: the National Comorbidity Survey. Am J Psychiatry 151: 979-986.

7. Merwin E, Hinton I, Dembling B, Stern S (2003) Shortages of rural menta health professionals. Arch Psychiatr Nurs 17: 42-51.

8. Seedat S, Scott KM, Angermeyer MC, Berglund P, Bromet EJ, et al. (2009) Cross-national associations between gender and mental disorders in the World Health Organization World Mental Health Surveys. Arch Gen Psychiatry 66: 785-795.

9. Amin S, Khan A (2009) Life in conflict: Characteristics of Depression in Kashmir Int J Health Sci 3: 213-223.

10. Banal R, Thappa J, Shah H, Hussain A, Chowhan A, et al. (2010) Psychiatric morbidity in adult Kashmiri migrants living in a migrant camp at Jammu. Indian J Psychiatry 52: 154

11. Chadda RK, Malhotra A, Kaw N, Singh J, Sethi H (2007) Mental health problems following the 2005 earthquake in Kashmir: findings of community-run clinics. Pre hospital and Disaster Medicine 22: 541-545

12. Yaswi A, Haque A (2008) Prevalence of PTSD symptoms and depression and level of coping among the victims of the Kashmir conflict. Journal of Loss and Trauma 13: 471-480.

13. Shaffer K (2014) Centre for Epidemiologic Studies Depression (CES-D) scale. Encyclopaedia of Quality of Life and Well-Being Research, pp: 637-640.
14. Chandran M, Tharyan P, Muliyil J, Abraham S (2002) Post-partum depression in a cohort of women from a rural area of Tamil Nadu, India. Br J Psychiatry 181: $499-504$

15. Shidhaye R, Patel V (2010) Association of socio-economic, gender and health factors with common mental disorders in women: a population-based study of 5703 married rural women in India. Int J Epidemiol 39: 1510-1521.

16. Avison WR, McAlpine DD (1992) Gender differences in symptoms of depression among adolescents. J Health Soc Behav 33: 77-96.

17. Tekur P, Nagarathna R, Chametcha S, Hankey A, Nagendra H (2012) A comprehensive yoga programs improves pain, anxiety and depression in chronic low back pain patients more than exercise: An RCT. Complementary Ther Med 20: 107-118.

18. Burns JR, Rapee RM (2006) Adolescent mental health literacy: young people's knowledge of depression and help seeking. J Adolesc 29: 225-239.

19. Berkman ND, Sheridan SL, Donahue KE, Halpern DJ, Crotty K (2011) Low health literacy and health outcomes: an updated systematic review. Ann Inten Med 155: 97-107.

20. Horwath U, Szczerbinska K (2017) Determinants of late-life depression in residents of long-term care facility. Pol Merkur Lekarski 43: 213-219.

21. Miech RA, Shanahan MJ (2000) Socio-economic status and depression over the life course. J Health Soc Behav 41: 162-176.

22. Mirowsky J, Ross CE (2001) Age and the effect of economic hardship on depression. J Health Soc Behav 42: 132-150.

23. Kessler RC, Berglund P, Demler O, Jin R, Koretz D, et al. (2003) The epidemiology of major depressive disorder: results from the National Comorbidity Survey Replication (NCS-R). JAMA 289: 3095-3105.

24. Alonso J, Angermeyer MC, Lépine JP (2004) The European study of the Epidemiology of mental disorders (ESEMeD) project. Acta Psychiatrica Scandinavica 109: 5-7

25. Griffiths RA, Good WR, Watson NP, O'Donnell HF, Fell PJ, et al. (1987) Depression, dementia and disability in the elderly. $\mathrm{Br} \mathrm{J}$ Psychiatry 150: 482493.

26. Kok RM, Reynolds CF (2017) Management of Depression in Older adults: A review. JAMA 317: 2114-2122.

27. Lindbo A, Gustafsson M, Isaksson U, Sandman PO, Lovheim H (2017) Dysphoric symptoms in relation to other behavioural and psychological symptoms of dementia, among elderly in nursing homes. BMC Geriatr 17: 206

28. Patra P, Alikari V, Fradelos EC, Sachlas A, Kourakos M, et al. (2017) Assessment of depression in elderly. Is perceived social support related? A nursing home study: Depression and social support in elderly. Adv Exp Med Biol 987: 139-150.

29. Richard A, Rohrmann S, Vandeleur CL, Schmid M, Barth J, et al. (2017) Loneliness is adversely associated with physical and mental health and lifestyle factors: Results from a Swiss national survey. PLoS One 12: e0181442.

30. Valkanova V, Ebmeier KP, Allan CL (2017) Depression is linked to dementia in older adults. Practitioner 261: 11-15

31. Oliffe JL, Hannan-Leith MN, Ogrodniczuk JS, Black N, Mackenzie CS, et al. (2016) Men's depression and suicide literacy: a nationally representative Canadian survey. J Ment Health 25: 520-526.

32. Pekmezi D, Ainsworth C, Holly T, Williams V, Benitez T, et al. (2017) Rationale, design, and baseline findings from a pilot randomized trial of an IVR-Supported physical activity intervention for cancer prevention in the Deep South: the DIAL study. Contemp Clin Trials Commun 8: 218-226. 